
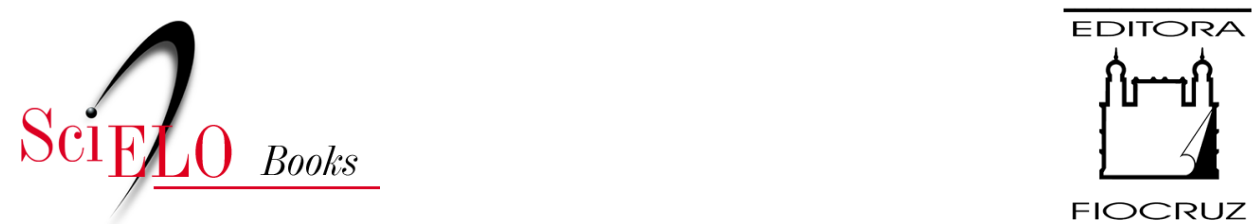

FIOCRUZ

\title{
Introdução: uma história institucional das ciências no Brasil
}

\author{
Maria Amélia M. Dantes
}

\section{SciELO Books / SciELO Livros / SciELO Libros}

DANTES, M. A. M. Introdução: uma história institucional das ciências no Brasil. In: DANTES, M. A. M., ed. Espaços da Ciência no Brasil: 1800-1930 [online]. Rio de Janeiro: Editora FIOCRUZ, 2001,pp. 13-22. História e saúde collection. ISBN: 978-65-5708-157-0. https://doi.org/10.7476/9786557081570.0002.

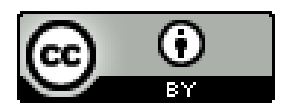

All the contents of this work, except where otherwise noted, is licensed under a Creative Commons Attribution 4.0 International license.

Todo o conteúdo deste trabalho, exceto quando houver ressalva, é publicado sob a licença Creative Commons Atribição 4.0.

Todo el contenido de esta obra, excepto donde se indique lo contrario, está bajo licencia de la licencia Creative Commons Reconocimento 4.0. 


\title{
Introdução:
}

\section{uma históría institucional das ciências no Brasil}

\author{
Maria Amélia M. Dantes
}

\begin{abstract}
A palavra atividade científica expressa (...) uma realidade concreta, aqui e agora, em que as idéias existem sempre ligadas a homens e instituições; seu estudo nos coloca frente ao problema do tempo e do espaço histórico e nos obriga a um diálogo concreto, preciso, profundo com as fontes manuscritas e documentais que estão guardadas em nossas bibliotecas e arquivos.
\end{abstract}

Antonio Lafuente ${ }^{1}$

\section{A história da ciência e as instituições}

As instituições científicas vêm recebendo uma atenção secundária dos historiadores da ciência, que têm se dedicado prioritariamente ao estudo do desenvolvimento conceitual das ciências, visto como resultante de um processo autônomo, regido por normas internas e independente dos demais processos sociais.

As instituições científicas são aí consideradas como uma decorrência necessária do valor intrínseco do conhecimento verdadeiro, isto é, como espaços que são conquistados pelos cientistas e que passam a sediar suas atividades.

Assim, tradicionalmente, a história institucional da ciência tem se voltado, sobretudo, para algumas das dimensões sociais das práticas científicas, deixando para a história epistemológica as questões relacionadas à natureza do conhecimento científico.

Este quadro dicotômico - questões do conhecimento e questões sociais - persistiu até os anos 70. É representativa desta permanência a obra do sociólogo da ciência Joseph Ben-David que, em seu livro de 
1971, O Papel do Cientista na Sociedade, dedicado ao estudo das formas organizacionais e papéis atribuídos às ciências em diferentes períodos históricos, assim se expressa:

embora as sociedades possam acelerar ou retardar o crescimento científico ao dar ou negar apoio à ciência ou a alguns de seus aspectos, podem fazer relativamente pouco para dirigir o seu curso. Este é determinado pelo estado conceitual da ciência e pela criatividade individual - e estes aspectos seguem suas leis próprias, sem aceitar ordens ou subornos. (Ben-David, 1974:25)

No entanto, nos anos 70, já estavam ocorrendo transformações conceituais nos estudos históricos e sociológicos da ciência que apontavam, entre outras coisas, para um redimensionamento da história institucional.

Estas mudanças eram indicadas pelo historiador norte-americano Roger Hahn em sua obra pioneira sobre a Academia de Ciências de Paris, em que chama a atenção para a importância histórica das instituições científicas e as considera como espaços em que interesses sociais e científicos se encontram. No prefácio do livro, ele declara que " a instituição científica é a bigorna na qual são moldados, em uma forma viável, os valores muitas vezes conflitantes, da ciência e da sociedade" (Hahn, 1971:X).

Ou seja, para Hahn, as instituições científicas desempenham um papel fundamental na implantação de práticas e conhecimentos científicos e seu estudo pode ser esclarecedor sobre os diferentes fatores presentes neste processo.

Também nos anos 70, os debates instaurados por sociólogos, historiadores e filósofos sediados em instituições inglesas e escocesas traziam novas perspectivas para a historia institucional. Estes autores tinham por objetivo ultrapassar os limites vigentes na sociologia da ciência e declaravam que as várias dimensões das ciências, até mesmo seus conteúdos, são influenciados por fatores sociais. Mais ainda, defendiam a conceituação das ciências como práticas, e dos conhecimentos científicos como construções que se estabelecem socialmente. ${ }^{2}$

Os estudos empíricos realizados pelos seguidores dos Estudos Sociais do Conhecimento - Social Studies of Knowledge (SSK) - voltaram-se sobretudo para a análise da influência de fatores extracientíficos no processo de produção de conhecimentos. Uma avaliação das pesquisas realizadas nos v́ltimos vinte anos revela que a dimensão institucional tem estado pouco presente nesta vertente historiográfica e sociológica. No entanto, estes 
estudos têm trazido implicações metodológicas muito frutíferas para a história das instituições científicas, pois, como bem enfatiza o historiador espanhol Antonio Lafuente, cujas palavras abrem esta introdução, a conceituação de ciência, como uma prática concreta, remete o historiador aos cientistas - homens e mulheres, sujeitos de um determinado espaçotempo social - e também aos espaços institucionais que sediam suas práticas.

Assim, do ponto de vista da produção historiográfica, a história institucional da ciência é ainda iniciante. Mesmo em países com maior tradição científica, como os europeus, somente nas últimas décadas algumas das mais importantes instituições científicas começaram a ser estudadas de forma sistemática. O caso francês é bem ilustrativo. Nesse país, somente nos últimos anos, por estímulo da atuação de historiadores ingleses e norteamericanos, tem sido produzida uma historiografia significativa sobre instituições científicas renomadas como a Escola Politécnica de Paris, a Escola Normal Superior e o Museu de História Natural. ${ }^{3}$

O livro de Roger Hahn, citado anteriormente, é, assim, um dos pioneiros de uma vertente historiográfica, hoje, bastante florescente.

\section{A história da ciência no Brasil no contexto da nova historiografia}

Em relação à História da Ciência no Brasil, há uma outra questão a ser considerada: foi somente a partir da década de 80 que se desenvolveram, de forma significativa, estudos sobre o processo de implantação de atividades científicas em países que não ocuparam papéis de liderança no processo de produção de conhecimentos.

Para o desenvolvimento desta área foi, sem dúvida, fundamental a mudança que ocorria na historiografia da ciência e que apontava para uma valorização da história social. Também, na segunda metade do século XX, as ciências e tecnologias ganharam grande destaque nas políticas estatais, o que estimulou a formação de estudiosos - filósofos, historiadores, sociólogos - destas áreas do conhecimento. Foi justamente esta nova geração que passou a se dedicar ao estudo da história da ciência em seus países.

O primeiro texto a trabalhar de forma mais abrangente o tema da difusão da ciência nos vários continentes foi o artigo do historiador norteamericano George Basalla, The Spread of Western Science, de 1967, que entendia a introdução da ciência nos vários países como um caminho inevitável, resultante da superioridade cognitiva da ciência moderna. 
O estudo de Basalla, apesar de bastante questionado, estimulou estudos sobre os mecanismos de difusão científica e a implantação de atividades científicas nos diferentes contextos nacionais. Duas vertentes merecem destaque. Primeira, os estudos sobre o papel desempenhado pelas ciências nas políticas imperialistas de países como Inglaterra, França e Alemanha. ${ }^{4}$ Também, os estudos sobre os vários contextos nacionais, que tenderam a uma crítica à visão difusionista de Basalla, e enfatizaram as dinâmicas sociais locais e sua influência nas formas assumidas pelas práticas científicas. ${ }^{5}$

A historiografia latino-americana dos últimos vinte anos tem estado integrada a estas mudanças teóricas e temáticas. Um dos canais de integração foi a criação, em 1982, da Sociedade Latino-Americana de História da Ciência e Tecnologia, que vem se constituindo em importante espaço de intercâmbio dos historiadores do continente. A revista da sociedade, Quipu, é testemunho dos estudos que vêm sendo realizados sobre as várias nações.

Entre as antigas colônias, os Estados Unidos da América é o país com maior tradição em história da ciência nacional. Em outras regiões em especial, no Japão e na Índia, entre os países asiáticos; e na Austrália e Nova Zelândia, na Occania - existem hoje, também, comunidades de historiadores que vêm se dedicando a estes estudos. ${ }^{6}$

A historiografia brasileira mais recente também tem caminhado neste sentido. Vejamos como.

\section{A história das ciêencias no Brasil e as instituições cientifificas}

O desenvolvimento de uma produção historiográfica sobre as atividades científicas no Brasil é relativamente recente. Podemos lembrar, para um período mais recuado, algumas obras memorialísticas, escritas sobretudo por cientistas, que buscavam registrar trajetórias individuais ou de institutos, associações ou escolas existentes no país. ${ }^{7}$

O livro As Ciências no Brasil, organizado, nos anos 50, por Fernando de Azevedo, constituiu o primeiro estudo abrangente que, de um ponto de vista sociológico, procurava compreender o desenvolvimento das áreas científicas no país (Azevedo, s.d.). No entanto, esta obra ainda se situava na tradição de uma história da ciência voltada para a formulação de grandes 
teorias e que pensava as regiões periféricas como receptáculos passivos da ciência produzida nos grandes centros, em especial os europeus.

Como um marco da história institucional das ciências no Brasil deve ser registrada a edição, em 1975, do livro da historiadora inglesa Nancy Stepan, Beginnings of Brazilian Science, no qual a autora, a partir do estudo do Instituto Oswaldo Cruz do Rio de Janeiro, analisa o papel desempenhado pelas instituições científicas, cientistas e Estado brasileiro, na formação de uma tradição em ciência experimental no país (Stepan, 1975).

O final dos anos 70 viu surgirem algumas obras de autores brasileiros, como Formação da Comunidade Científica no Brasil (1979), editada por Simon Schwartzmann, e História das Ciências no Brasil (1979-1981), em três volumes editados por Mário Guimarães Ferri e Shozo Motoyama, que se propunham a analisar a implantação das diferentes áreas científicas no país e a contribuir para os debates sobre as relações entre ciência, tecnologia e desenvolvimento nacional.

Mesmo assim, até meados da década de 80 , poucas instituições científicas brasileiras haviam merecido um estudo mais aprofundado. ${ }^{8}$

Mais ainda, nesses anos, permanecia difundida, entre os historiadores, a conviç̧ão de que, antes da criação das primeiras universidades brasileiras, nos anos 30, os institutos de ciências biomédicas haviam sido os únicos centros de pesquisa realmente relevantes para a história das ciências no Brasil. ${ }^{9}$ No entanto, esta primeira produção historiográfica já registrava a existência no país, desde o período colonial, de uma variedade imensa de instituições científicas.

O livro de Schwartzmann (1979) ilustra bem este ponto. Nele é apresentada, em apêndice, uma cronologia da ciência brasileira, correspondente ao período de 1500 a 1945 que, a partir das informações contidas no livro editado por Fernando de Azevedo, apresenta uma relação de eventos relativos a dois temas da história das ciências no Brasil: institucionalização e produção científica.

A listagem referente ao primeiro tema começa com o período colonial e registra um número significativo de espaços dedicados a atividades científicas. ${ }^{10}$

Para o século XIX está registrada a criação, durante a permanência da Corte portuguesa no Rio de Janeiro, de diversas instituições, muitas das quais atuantes ainda hoje, tais como as escolas médico-cirúrgicas da Bahia e do Rio de Janeiro, de 1808, que, em 1832, se transformaram em faculdades de medicina; a Academia Real Militar, de 1810, que deu origem à Escola 
Central em 1858 e à Escola Politécnica do Rio de Janeiro em 1874; um horto, em 1808, depois Jardim Botânico do Rio de Janeiro; em 1818, um museu de história natural, depois Museu Imperial e atual Museu Nacional da Universidade Federal do Rio de Janeiro.

Estão também aí registrados espaços privados de atuação na área cultural, científica e técnica, como a Sociedade Auxiliadora da Indústria Nacional, de 1825, e o Instituto Histórico e Geográfico Brasileiro, de 1838, com suas publicações, O Auxiliador, editado até os anos 90 do século XIX e a Revista do IHGB, que existe até a atualidade.

Ainda no Império, consta também da cronologia o conjunto de medidas governamentais que ampliaram significativamente os espaços científicos nos anos 70 do século XIX, quando foram reformados o Museu Imperial e as escolas profissionais, bem como ganhou autonomia o Observatório Astronômico. No período final do Império, aparece a criação de instituições variadas, como a Escola de Minas de Ouro Preto, de 1875; a Comissão Geológica do Império, que atuou de 1875 a 1877; a Comissão Geográfica e Geológica de São Paulo, de 1886, e a Imperial Estação Agronômica, de 1887, depois Instituto Agronômico de Campinas.

Pode-se visualizar, assim, para o século XIX, o crescimento continuado dos espaços dedicados à ciência no Brasil imperial.

Os registros relativos aos primeiros anos do período republicano mostram como a descentralização administrativa estimulou a criação, pelos governos estaduais, de uma variedade de escolas profissionais. Registram também a atuação dos primeiros institutos bacteriológicos, o de São Paulo, de 1892, e o do Rio de Janeiro, de 1900.

Entrando pelo século $\mathrm{XX}$, a cronologia registra uma série crescente de escolas profissionais e de instituições de pesquisa. Cita também a criação, em 1916, da Sociedade Brasileira de Ciências, atual Academia Brasileira de Ciências, uma associação científica de caráter nacional.

Como vemos, a presença de instituições científicas no Brasil já estava registrada na historiografia dos anos 70 . No entanto, o reconhecimento do papel desempenhado por estes espaços na implantação das ciências só se deu a partir de uma mudança de perspectiva metodológica.

Um primeiro sinal desta mudança já aparecia no livro de Stepan (1975) sobre o Instituto Oswaldo Cruz, quando a autora chamava a atenção para a necessidade de se valorizar mais o papel que esta instituição havia desempenhado no país do que no cenário internacional. Isso mostra a 
aproximação de Stepan com os estudos de história social da ciência dos anos 70 , que se voltavam para o estudo das condições sociais de implantação das atividades científicas.

Nesta linha, a partir da crítica ao anacronismo até então presente na historiografia brasileira e procurando trabalhar com os critérios de cientificidade do período estudado, historiadores brasileiros dos anos 80 e 90 realizaram estudos detalhados sobre algumas das mais importantes instituições científicas brasileiras do século XIX e início do século XX.

Entre instituições públicas estudadas, podem ser lembradas: o Museu Nacional de História Natural, o Museu Paraense, o Museu Paulista, a Faculdade de Medicina do Rio de Janeiro, a Comissão Geológica de São Paulo, a Imperial Estação Agronômica de Campinas, o Instituto Bacteriológico de São Paulo e o Instituto Butantan. ${ }^{11}$ Entre os espaços privados, em geral criados por grupos de profissionais: a Academia Imperial de Medicina, as revistas médicas, os institutos agrícolas e a Academia Brasileira de Ciências. ${ }^{12}$

Com as pesquisas, novos espaços científicos foram se revelando, como a Sociedade Vellosiana, uma associação criada por naturalistas brasileiros em 1850 e que subsistiu por alguns anos. ${ }^{13}$

Os estudos se acumularam, mas são ainda majoritariamente voltados para instituições do Rio de Janeiro, antiga Corte e capital federal, e São Paulo. Só nos últimos anos este quadro está mudando e começam a aparecer textos sobre instituições de outras regiões do país.

Estas pesquisas invalidam algumas das afirmativas presentes na historiografia brasileira até 1980 , como a de que o período que precedeu as universidades brasileiras havia sido uma 'pré-história' da ciência no Brasil. Ou a de que, no século XIX, não existissem, no país, grupos sociais interessados e que apoiassem as atividades científicas. ${ }^{14}$

É justamente neste debate que este livro se insere, procurando contribuir para a divulgação dos estudos que vêm sendo realizados em história institucional da ciência no Brasil e apresentando uma amostragem desta área de estudos tão promissora. 


\section{Notas}

2 Sobre este movimento e suas implicações para a História da Ciência, ver Pestre, 1996. A conceituação de prática científica também é valorizada por Andrew Pickering, no texto From Science as Knowledge to Science as Practice, prefácio do livro por cle editado, Science as Practice and Culture (1992).

3 Ver, entre outros, Shinn, 1980; Fox \& Weisz, 1980; Zwerling, 1990. As obras de autores franceses são mais recentes, como as de Picon, 1992 e Belhoste, Dalmedico \& Picon, 1994.

4 São representativos destes estudos, os textos de Lewia Pyenson, sobre o imperialismo científico na Alemanha e França, e os estudos de Roy Macleod, sobre o papel da ciência no império britânico. Ver Pyenson, 1989 e Macleod, 1987.

5 Entre os autores latino-americanos, o colombiano Luiz Carlos Arboleda trata desta questão no artigo Acerca del Problema de la Difusión Científica en la Periferia: el caso de la física newtoniana en la Nueva Granada (1987). A coletânea editada por Antonio Lafuente, Alberto Elena e M. Luiza Ortega, Mundialización de la Ciencia y Cultura Nacional (1993), também apresenta uma variedade de estudos nesta vertente.

- Como uma amostra desta produção, hoje já bastante extensa, vide Petitjean, Jami \& Moulin, 1992.

7 Sobre a historiografia da ciência no Brasil, ver Garcia, Oliveira \& Motoyama, 1980.

8 Dos anos 70 é, também, o livro de José Murillo de Carvalho, A Escola de Minas de Ouro Preto: $o$ pêso da glória (1978).

9 Ver Dantes, 1980. Em meu artigo Institutos de Pesquisa Científica no Brasil, questiono esta posição e chamo a atenção para a atuação de instituições do século XIX e início do século XX.

10 O registro referente ao período colonial é pouco significativo, mas cste é um período ainda pouco estudado pelos historiadores da ciência. Pesquisas recentes têm trazido novas informações sobre a atuação de jesuítas no Brasil. Ver Camenietzki, 2000.

1 Ver Lopes, 1997; Figueirôa, 1997; Alves, 1998; Edler, 1992; Meloni, 1999; Benchimol, 1990; Benchimol \& Teixeira, 1993; Almeida, 1998.

12 Cf. Alves, 1989; Domingues, 1995; Ferreira, 1996.

13 As pesquisas realizadas por Maria Margaret Lopes nos arquivos do Museu Nacional da UFRJ, por exemplo, revelaram documentação inédita sobre esta primeira associação de naturalistas brasileiros. Ver Lopes, 1997. 


\section{Referências bibliográficas}

ALMEIDA, M. de. A República dos Invisiveis: Emílio Ribras, microbiologia e saúde pública em São Paulo (1898-1917), 1998. Dissertação de Mestrado, São Paulo: FFLCH-USP.

ALVES, A. M. A. Um Museu Científico na História de São Paulo: o Museu do Ipiranga, 1998. Dissertação de Mestrado, São Paulo: FFLCH-USP.

ALVES J. J. A. A Ciência: as atividades que se fizeram em seu nome (1920-1950), 1989. Tese de Doutorado, São Paulo: FFLCH-USP.

ARBOLEDA, L. C. Aderca del problema de la difusión científica en la periferia: el caso de la física newtoniana en la Nueva Granada. Quipu, 4(1):7-30, 1987.

AZEVEDO, F. de. (Org.) As Ciências no Brasil. 2.v. São Paulo: Ed. Melhoramentos, s.d.

BASALLA, G. The spread of western science. Science, 156: 611-622, 1967.

BELHOSTE, B.; DALMEDICO, A. D. \& PICON, A. (Eds.) La Formation Polytechnicienne, 19711994. Paris: Ed. Dunod, 1994.

BENCHIMOL, J. L. (Coord.) Manguinhos do Sonho à Vida: a ciência na belle époque. Rio de Janeiro: Casa de Oswaldo Cruz/Fiocruz, 1990.

BENCHIMOL, J. L. \& TEIXEIRA, L. A. Cobras, Lagartos \& Outros Bichos: uma história comparada dos Institutos Oswaldo Cruz e Butanatan. Rio de Janeiro: Fiocruz/UFRJ, 1993.

BEN-DAVID, J. O Papel do Cientista na Sociedade. São Paulo: Pioneira, 1974.

CAMENIETZKI, C. Z. A Companhia de Jesus e a ciência na América portuguesa entre 1663 c 1679. IIl Seminário Nacional de História da Matemática. Anais... Vitória, 2000.

CARVAlHO, J. M. de. A Escola de Minas de Ouro Preto: o pêso da glória. São Paulo: Companhia Editora Nacional, 1978.

DANTES, M. A. M. Institutos de Pesquisa Científica no Brasil. In: FERRI, M. G. \& MOTOYAMA, S. (Orgs.) História das Ciências no Brasil. v.2. São Paulo: Edusp/EPU, 1980.

DOMINGUES, H. M. B. Ciência, um Caso de Política: as relações entre as ciências naturais e agricultura no Brasil Império, 1995. Tese de Doutorado, São Paulo: FFLCH-USP.

EDLER, F. C. As Reformas do Ensino Médico e a Profissionalização da Medicina na Corte do Rio de Janeiro (1854-1884), 1992. Dissertação de Mestrado, São Paulo: FFLCH-USP.

FERREIRA, L. O. O Nascimento de uma Instituição Científica: o periódico médico brasileiro da primeira metade do século XIX, 1996. Tese de Doutorado, São Paulo: FFLCH-USP.

FERRI, M. G. \& MOTOYAMA, S. (Orgs.) História das Ciências no Brasil. 3.v. São Paulo: Edusp/ EPU, 1979.

FIGUEIRÔA, S. F. M. As Ciências Geológicas no Brasil: uma história social e institucional, 18751934. São Paulo: Hucitec, 1997.

FOX, R. \& WEISZ G. (Eds.) The Organization of Science and Tecnology in France, 1808-1914. Cambrige: Cambrige University Press, 1980.

GARCIA, J. C.; OLIVEIRA J. C. \& MOTOYAMA S. O desenvolvimento da história da ciência no Brasil. In: FERRI, M. G. \& MOTOYAMA, S. (Orgs.) História das Ciências no Brasil. 2.v. São Paulo: Edusp/EPU, 1980. 
HAHN, R. The Anatomy of a Scientific Institution: the Paris Academy of Sciences, 1666-1803. Berkeley: University of California Press, 1971.

LAFUENTE, A. La ciencia periférica y su especialidad historiográfica. In: SALDAÑA, J. J. \& LAFUENTE, A. (Eds.) El Perfil de la Ciencia en América. México: Ed. Cuadernos Quipu, 1986.

LAFUENTE, A.; ELENA, A. \& ORTEGA, M. L. Mundialización de la Ciencia y Cultura Nacional. Madrid: Ed. Doce Calles, 1993.

LOPES, M. M. O Brasil Descobre a Pesquisa Científica: os museus e as ciências naturais no século $X I X$. São Paulo: Hucitec, 1997.

MACLEOD, R. On visiting the moving metropolis: reflections on the architecture of imperial science. In: REINGOLD, N. \& ROTHEMBERG, M. (Eds.) Scientific Colonialism: a cross cultural comparison. Washington: Smithsonian Institution Press, 1987.

MELONI, R. Ciência e Produção Agrícola: a imperial estação agronômica de Campinas (1887-1897), 1999. Dissertação de Mestrado, São Paulo: FFLCH-USP.

PESTRE, D. Por uma Nova História Social e Cultural das Ciências: novas definições, novos objetos, novas abordagens. Cadernos IG-Unicamp, 6:3-56, 1996. (Ed. Francesa: Annales ESC, 50(3), mai.-juin., 1995).

PETITJEAN, P.; JAMI, C. \& MOULIN, A. M. (Eds.) Science and Empires: historical studies about scientific development and European expansion. Dordrecht: Kluver Academis Publishers, 1992.

PICKERING, A. From science as knowledge to science as pactice (Prefácio). In: PICKERING, A. (Ed.) Science as Practice and Culture. Chicago: University of Chicago Press, 1992.

PICON, A. L'Invention de l'Ingénieur Moderne: l'école des ponts et chaussées, 1747-1841. Paris: Presses de l'École Nationale des Ponts et Chaussées, 1992.

PYENSON, L. Pure learning and political economy: science and European expansion in the age of imperialism. In: Proceedings of the Utrecht Conference, New Trends in the History of Science. Amsterdam: Rodopi, 1989.

SCHWARTZMANN, S. Formação da Comunidade Científica no Brasil. São Paulo: Companhia Editora Nacional, 1979.

SHINN, T. Savoir Scientifique et Pouvoir Social-l'École Polytechnique, 1794-1914. Paris: Fondation Nationale des Sciences Politiques, 1980.

STEPAN, N. Beginings of Brazilian Science. Nova Iorque: Science History Publications, 1975.

ZWERLING, C. S. The Emergence of the École Normale Supérieure as a Center of Scientific

Education in $19^{\text {th }}$ Century France. Nova Iorque: Garland Publishing Inc., 1990. 